\title{
Early Detection of Chronic Obstructive Pulmonary Disease (COPD) in Family Practice
}

\author{
Hani A. Jokhdar ${ }^{1}$, Mohammed A. Garout ${ }^{1}$, Mohammad M. Alkot ${ }^{2, *}$, Rana H. El-Helbawy ${ }^{3}$, \\ Jehad O. Albitar ${ }^{4}$ \\ ${ }^{1}$ Community Medicine and Pilgrimage Health Care Department, Umm Al-Qura University, Makkah Al-Mukaramah, Saudi Arabia \\ ${ }^{2}$ Family Medicine Department, Menoufia University, Shebien Elkoum, Egypt \\ ${ }^{3}$ Chest Department, Menoufia University, Shebien Elkoum, Egypt \\ ${ }^{4}$ Internship, Umm Al-Qura University, Makkah Al-Mukaramah, Saudi Arabia
}

\section{Email address:}

Hani_j@me.cm (H. A. Jokhdar),dr.m.garout@gmail.com (M. A. Garout), Ranaelhelbawy@yahoo.com (R. H. El-Helbawy), dr.jehad@live.com (J. O. Albitar)

${ }^{*}$ Corresponding author

\section{To cite this article:}

Hani A. Jokhdar, Mohammed A. Garout, Mohammad M. Alkot, Rana H. El-Helbawy, Jehad O. Albitar. Early Detection of Chronic Obstructive Pulmonary Disease (COPD) in Family Practice. Journal of Family Medicine and Health Care. Vol. 3, No. 1, 2017, pp. 1-5. doi: $10.11648 /$ j.jfmhc.20170301.11

Received: September 20, 2016; Accepted: November 22, 2016; Published: December 27, 2016

\begin{abstract}
Background: In real practice, Chronic Obstructive Pulmonary Diseases (COPD) is often diagnosed at a late stage as its clinical manifestations pass unnoticed and spirometry is almost not utilized. Objectives: To clarify the possibility of early detection of COPD by family physicians at the primary health care level. Methods: The study was conducted during the winter season (2015) in Al-Shohadaa family health center, Al-Shohadaa city, Menoufia governorate, Egypt. All patients $\geq 40$ years, smoking $\geq 20$ pack-years and attending the center with respiratory symptoms were subjected after their consent to a spirometry to check for early COPD diagnosis. Results: Although based on spirometry 33 out of 192 had COPD (18 (9.4\%) had GOLD I and $15(7.8 \%)$ had $\geq$ GOLD II, respectively), there was no significant difference in the type and the number of respiratory symptoms between Non-COPD and early COPD patients. Conclusion: It was demonstrated that the presenting symptoms specially in early stages could not discriminate the patients with COPD, so availability of spirometry in addition to training of family physicians at the family health care settings is a mandatory challenge for early diagnosis of COPD.
\end{abstract}

Keywords: Chronic Obstructive Pulmonary Diseases, Spirometry, GOLD Guidelines, Family Practice

\section{Introduction}

There is a lack of a satisfactory definition of Chronic Obstructive Pulmonary Diseases (COPD) that hampered its scientific evaluation and public understanding [1]. All international organizations, including the American Thoracic Society, European Respiratory Society, World Health Organization/National Heart, Lung, and Blood Institute in addition to Global Obstructive Lung Disease Initiative (GOLD) stated that COPD should be defined at physiological bases. Typical of these definitions, British Thoracic Society defines COPD as a slowly progressive disorder that characterized by airflow obstruction which does not vary markedly over several months of observation. Most of the lung function impairments are fixed [reduced both FEV1 (Forced Expiratory Volume in the first second) and FEV1/FVC (Forced Vital Capacity) ratio], although some therapeutic reversibility can be produced. [2]

COPD is a major cause of mortality and morbidity across the world, and the disease burden is suspected to increase in the next twenty years. COPD will be the 5 th leading cause of morbidity and the 3rd leading cause of mortality in the coming decades [3]. The impact of COPD in Egypt and world encourage the developing of successful strategies to early identify the illness, early management and subsequently reduce its impact. [4]

Despite spirometry is the most important tool to confirm the presence of airflow obstruction and to assess its severity, 
it is evident that it is not routinely used to diagnose COPD at the primary health care level $[5,6]$. This study was carried out to assess the importance of implementation of spirometry testing tool in family practice in addition to the clinical assessment for the early detection and diagnosis of COPD among patients who aren't previously diagnosed and aren't actually treated for chronic chest illnesses.

\section{Methods}

A cross-section study was carried out at the family health center of Al-Shohadaa city, Menoufia governorate, Egypt. The study was ethically approved by the Ethical Committee of the Faculty of Medicine, Menoufia University, Egypt. The study was conducted on the patients attending the site of the study during the winter season (2015) after their consent with the following inclusion criteria : (1) Age $\geq 40$ years, (2) Having a history of smoking and ex-smoking of $\geq 20$ packyears, and (3) Complaining of at least one respiratory symptom (daily dry or wet cough, dyspnea on exertion, wheezing, or frequent chest infections). However, the patients were excluded if they previously diagnosed as COPD and/or they were on respiratory medications. The patient who has these three criteria was referred to the chest clinic of Menoufia University hospital to undergo a spirometry test. For each patient who tested positive on spirometry tests, a post-bronchodilator test was done. Results of the spirometry were then reviewed and the presence or absence of COPD diagnosis was established (Figure1). "COPD" was defined as patients having FEV1/FVC $<0.7$ and FEV $1 \geq 80 \%$ of predicted normal value, that is, GOLD stage I, and FEV $1<80 \%$, that is GOLD stage $\geq$ II. Patients were categorized according to the updated GOLD guidelines (2014) into Non-COPD, GOLD stage I COPD and GOLD stage $\geq$ II COPD [7].

The quantity of smoking exposure was measured based on the smoking index, which was calculated as the product of the average number of cigarettes smoked per day and the duration of smoking in years. In Egypt, where a pack of cigarettes contains twenty ones, the smoking index is more appropriate than pack years. In comparative terms, 20 pack years is equivalent to a smoking index of 200 (Smoking index $=$ Pack years $\times 20$ ).

All targeted subjects were subjected to spirometry using a portable spirometer. Spirometry was performed by a welltrained person as per the recommendations of American Thoracic Society. FEV1/FVC and FEV1\% were measured after administration of $400 \mu \mathrm{g}$ of beta 2 agonist as salbutamol or terbutaline by inhalation devices as per the GOLD guidelines. Based on spirometry, patients were classified as having mild COPD (FEV1/FEVC $<0.70, \mathrm{FEV} \geq 80 \%$ of the predicted normal value), moderate COPD (FEV1/ FVC $<0.70$, FEV1 $79-50 \%$ of predicted normal value), sever COPD (FEV1/ FVC $<0.70$, FEV1 49-30\% of predicted normal value) and very severe COPD (FEV1/FVC $<0.70$, FEV $1<30 \%$ of predicted normal value) as per GOLD guidelines. Patients with abnormal spirometry results were advised to report back to the center for further evaluation, management, follow up and joining a smoking cessation programs later on.

For evaluation of early diagnostic tool of COPD (Spirometry testing in addition to analysis of the presenting symptoms and its discriminative value), the frequency of symptoms was

analyzed depending on the presence versus absence of GOLD I and $\geq$ II COPD. Symptoms at the time of presentation and its cumulative number were analyzed to assess its statistical relevance.

\section{Statistical Analysis}

The results were collected, tabulated and statistically analyzed using SPSS software program (Statistical Package for Social Science), Version 20. Quantitative data were expressed as a mean and standard deviation (mean $\pm \mathrm{SD}$ ). Qualitative data were expressed as numbers and percentages. To assess the differences in frequencies on the dichotomized qualitative variables Chi-Square test $\left(\chi^{2}\right)$ (fisher's exact test used when the frequencies were less than 5) was used. Two tailed t-test was used for comparing the means and SD between two groups however the ANOVA test was used for comparing three qualitative categorical groups. Results were considered positive at a $\mathrm{p}$-value $\leq 0.05$.

\section{Results and Discussion}

This study was conducted on 192 adult patients (Mean age $\pm \mathrm{SD}$ ) was $53.81 \pm 10.14$ with different socioeconomic levels complaining of chest symptoms (Table 1). This study is one of the first to assess and report on using spirometry in family health care settings. Previous studies have investigated the utilization of spirometry in the family health care practice from different aspects. Some have explored the role played by the management team and required a well-trained person to conduct the test [8] while others have not considered prescreening the patients to detect the ones who are at risk for developing COPD and did spirometry on all participants $[5,9]$. However, this study had a different approach, to avoid time-consuming unnecessary tests which should be restricted to a targeted population at a high risk of developing COPD. Screening patients with chest symptoms and selection of suspected patients (target patients) with a questionnaire based on the Canadian Lung Health Test and then performing pulmonary function tests (spirometry) to avoid unnecessary prescriptions of respiratory medications. [5, 9,10].

A gap has been recognized in the different studies about the need to decide whether or not the clinical symptoms and signs could be alone used in the family health care settings to confirm the diagnosis of COPD [11].

In real practice, there is still a concern by a great percentage of family physicians that pulmonary function tests (spirometry) may not be required for patients having smoking history and presenting with chest symptoms. This study strengthens the need of spirometry to create an early detection and COPD diagnosis, as clinical symptoms alone are not enough. A device as spirometry could be used to 
standardize the need for a diagnostic pulmonary function tests to be done. The most recent GOLD guidelines recommendations for the establishment of the diagnosis and management of COPD have clarified that spirometry is required to confirm the clinical diagnosis of COPD. [12]

There is no significant difference between Non-COPD group and either GOLD stage 1or stage $\geq 11$ COPD regarding the clinical symptoms and signs (Table 2). However, there is a significant difference between these groups regarding their pulmonary function tests (Tale 3 ). That means in early stages of COPD symptoms and signs alone are not enough to discriminate COPD from Non-COPD patients who are presented with more or less similar respiratory symptoms and signs. These results agree with a Canadian study (2014) [13].

In comparison to many previous studies that concentrate on secondary health care levels, spirometry was done outside the regular care and appointment. An important strength of this study is its generalizability in actual practice. This study focused on applying a system within real life family health care practices that depending on the results of spirometry that done for target patients. This study spotlights on the fact that conducting spirometry should not be considered as an easy process in family health care facilities even in the presence of health professionals' support. These professionals not only need to be trained but also require allocated time and may not be confident enough to maintain that role if they do not have sufficient exposure. Other challenges facing spirometry are the calibration that is not routinely performed and can lead to false results [14], also the short expiration time that may be insufficient enough to produce valid tests [15]. These obstacles slowed down the implantation of spirometry testing in the family health care settings in many countries. This study has confirmed in an actual life setting of family medicine that respiratory symptoms reported by smoker or ex-smoker patients are not reliable at discriminating COPD from Non-COPD patients (Table 2) especially in early stages of the disease which can be early detected by pulmonary function tests (Table 3 ). So the availability of spirometry for early detection of COPD in family practice is a great challenge to identify the illness with a high degree of specificity and sensitivity, to offer an effective intervention that would prevent, or at least delay the consequences of the illness.

\section{Limitations of the study}

Although some important recommendations can be reached by this study, it is worth appreciating the limitations and boundaries. Some studies have investigated the interpretation of pulmonary function tests (spirometry' results) by family physicians and found a high misdiagnosis rate $[9,10]$ however this study did not address this point as the spirometry' results were interpreted by a respirologist. Another limitation is that the study did not carried out interviews to assess qualitatively how the implementation process can be achieved all over the family health facilities. Early detection and treatment of COPD are clearly important.

\section{Conclusion}

Some alterations were needed to be done in our existing system. Having well qualified and trained family physicians together with the availability of pulmonary function testing tool (spirometry) can improve the rate of early detection and diagnosis of symptomatic COPD patients at the level of primary health care settings.

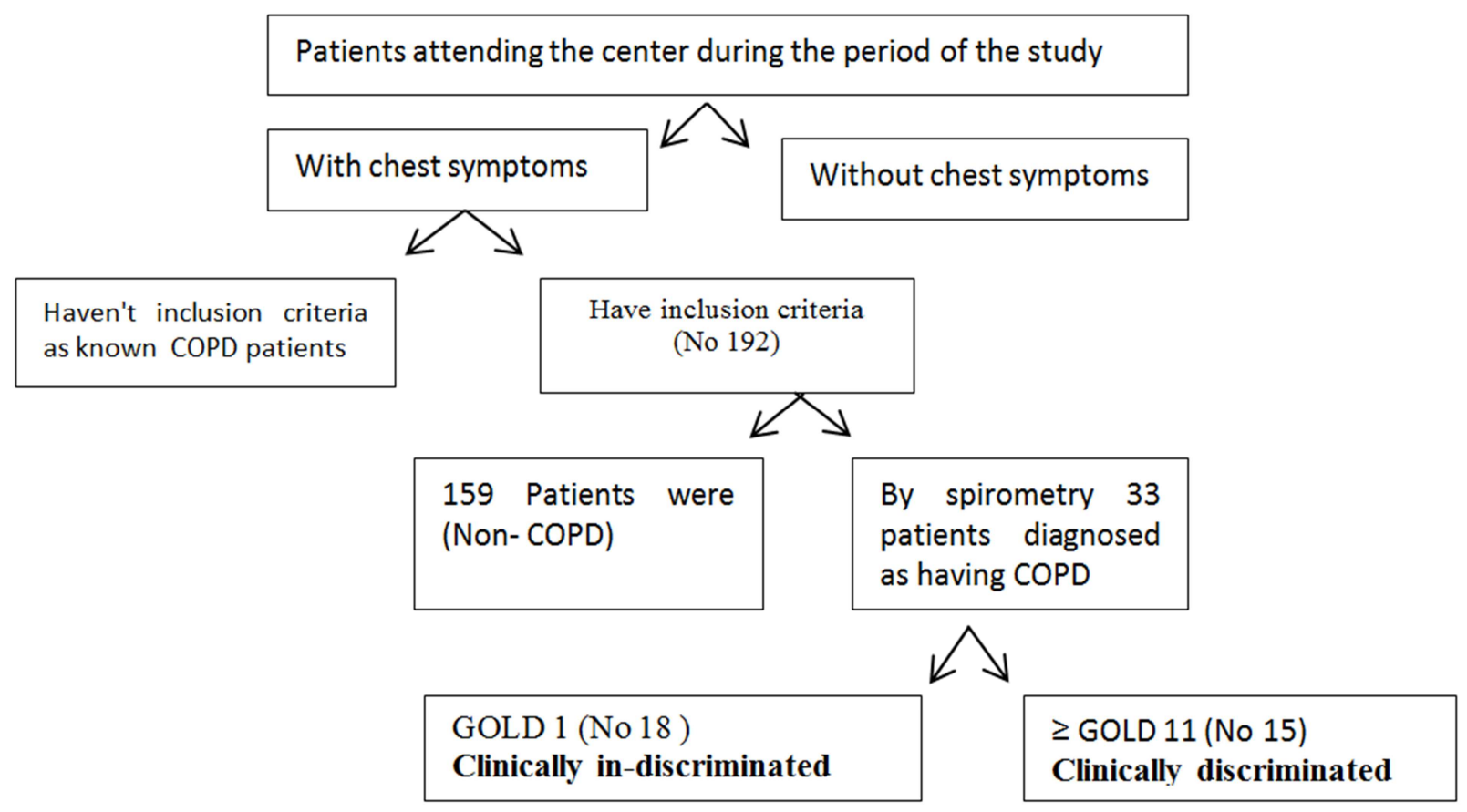

Figure 1. Flow chart of the study pathway. 
Table 1. Socioeconomic characteristics of studied patients.

\begin{tabular}{lll}
\hline Parameter & Cases (192) & \\
\hline Age (mean \pm SD & $53.81(10.14)$ & $\%$ \\
Marital status: & No & 53.12 \\
Married & 102 & 31.77 \\
Divorced & 61 & 15.62 \\
Widow & 30 & 4.68 \\
Single & 9 & 39.06 \\
education: & & 23.43 \\
Illiterate & 75 & 10.41 \\
Basic & 45 & 27.08 \\
Secondary & 20 & \\
University & 52 & 18.75 \\
Socioeconomic score: & & 18.22 \\
High & 36 & 63.02 \\
Medium & 35 & \\
low & 121 & \\
\hline
\end{tabular}

Table 2. Respiratory symptoms reported by the patients according to the spirometry-based diagnosis of COPD.

\begin{tabular}{|c|c|c|c|c|}
\hline Parameters & $\begin{array}{l}\text { Non- COPD } \\
\text { No } 159 \\
\end{array}$ & $\begin{array}{l}\text { COPD (GOLD I) } \\
\text { No } 18\end{array}$ & $\begin{array}{l}\text { COPD ( } \geq \text { GOLD II) } \\
\text { No } 15\end{array}$ & $P$ value ( $\chi^{2}$ test) \\
\hline *Symptoms, & (No and \%) & (No and \%) & (No and \%) & \\
\hline Cough & $112(70.44)$ & $12(66.66)$ & $9(60.00)$ & $>0.05$ \\
\hline Cough with sputum & $73(45.91)$ & $7(38.88)$ & $7(46.66)$ & $>0.05$ \\
\hline Dyspnoea & $123(77.35)$ & $11(61.11)$ & $10(66.66)$ & $>0.05$ \\
\hline Wheezing & $55(34.59)$ & $8(44.44)$ & $7(46.66)$ & $>0.05$ \\
\hline \multicolumn{5}{|l|}{ Number of symptoms } \\
\hline 0 & $5(3.14)$ & $1(5.55)$ & $0(0.00)$ & \\
\hline 1 & $43(27.04)$ & $5(27.77)$ & $5(33.33)$ & $>0.05$ \\
\hline 2 & $62(38.99)$ & $7(38.88)$ & $6(40.00)$ & $>0.05$ \\
\hline $3+$ & $48(30.18)$ & $5(27.77)$ & $5(33.33)$ & $>0.05$ \\
\hline
\end{tabular}

*Overlapping of results was recorded

Table 3. Spirometry diagnosis of COPD among targeted patient.

\begin{tabular}{|c|c|c|c|c|}
\hline Parameters & Non-COPD & COPD (GOLD I) & COPD ( $\geq$ GOLD II) & $P$ values (t. test) \\
\hline Age (in year), mean (SD) & $51.72(10.14)$ & $52.15(10.29)$ & $53.32(8.18)$ & $>0.05$ \\
\hline Smoking pack years, mean (SD) & $35.23(15.91)$ & $37.03(11.19)$ & $39.29(22.19)$ & $>0.05$ \\
\hline FEV1, $\%$ predicted, mean $(\mathrm{SD}) *$ & $89.78(15.11)$ & $71.06(7.72)$ & $58.12(12.08)$ & $<0.001$ \\
\hline FEV $1 / \mathrm{FVC} \%$, mean $(\mathrm{SD})^{*}$ & $79.33(11.28)$ & $59.74(2.80)$ & $45.33(7.33)$ & $<0.001$ \\
\hline
\end{tabular}

* P value of ANOVA test is $<0.05$

\section{References}

[1] Ford E, Mannino D, Wheaton A, Giles W, Presley-Cantrell L and Croft J. Trends in the prevalence of obstructive and restrictive lung function among adults in the United States: findings from the National Health and Nutrition Examination surveys.Chest.2013;143 (5):1395-1406.

[2] British Thoracic Society guidelines for the management of the chronic obstructive pulmonary disease. The COPD Guidelines Group of the Standards of Care Committee of the BTS. Thorax 1997; 52: S1-28.

[3] Murray C and Lopez A.: Mortality by cause for eight regions of the world. Global Burden of Disease Study. Lancet 1997; 349: 1269-1276.
[4] Azza F, Ashraf A, Ahmad A, Mohamed E, and Micheal F.: Prevalence and predictors of chronic obstructive pulmonary disease among high-risk Egyptians, Bronchology, 2015; 9, (1): 27-33.

[5] Walters J, Haydn E and Nelson M: "Factors associated with misdiagnosis of COPD in primary care," Primary Care Resp. Journal, vol. 20, no. 4, pp. 396-402, 2011.

[6] Dirven J, Tange H, Muris J, van Haaren K, Vink G, van Schayck O. Early detection of COPD in general practice: patient or practice managed? A randomized controlled trial of two strategies in different socioeconomic environments. Prim Care Respir J. 2013;22(3):331-337.

[7] Global Initiative for Chronic Obstructive Lung Disease (GOLD). Global Strategy for the Diagnosis, Management and Prevention of COPD 2013. Available online: $\mathrm{http}: / /$ www.goldcopd.org/ 
[8] Price D, Freeman D, Cleland J, Kaplan A, Cerasoli F. Earlier diagnosis and earlier treatment of COPD in primary care. Prim Care Respir J. 2011;20(1):15-22.

[9] Tantucci C, Modina D Lung function decline in COPD. Int J Chron Obstruct Pulmon Dis. 2012;7:95-99.

[10] Vestbo J, Hurd S, Agustí A, et al. Global strategy for the diagnosis, management, and prevention of chronic obstructive pulmonary disease: GOLD executive summary. Am J Respir Crit CareMed.2013;187(4):347-365.

[11] Lin K, Watkins B, Johnson T, Rodriguez J, and Barton M, "Screening for chronic obstructive pulmonary disease using spirometry: summary of the evidence for the U. S. preventive services task force," Annals of Internal Medicine, vol. 148, no. 7, pp. 535-543, 2008.

[12] National Institute for Clinical Excellence. Chronic obstructive pulmonary disease: management of chronic obstructive pulmonary disease in adults in primary and secondary care. 2010 update. Available from: http://guidance.nice.org.uk/CG101. Last accessed 16 July 2010.

[13] Nathalie S, Maria S, Katrina M, and Jean B, Early COPD Diagnosis in Family Medicine Practice: How to Implement Spirometry? International Journal of Family Medicine Volume 2014, Article ID 962901, 6 pages http://dx.doi.org/10.1155/2014/962901

[14] Schermer T, Verweij E, Cretier R, Pellegrino A, Crockett A, and Poels P, "Accuracy and precision of desktop spirometers in general practices," Respiration, vol. 83, no. 4, pp. 344-352, 2012.

[15] Schermer T, Crockett A and Poels P, "Quality of routine spirometry tests in Dutch general practices," The British Journal of General Practice, vol. 59, no. 569, pp. e376-e382, 2009 . 